\title{
Entrepreneurship, Higher Education and $R+D$ in Mexico
}

\section{Martín Ramírez-Urquidy, Alejandro Mungaray, Roberto Fuentes}

School of Economics and International Relations, Universidad Autónoma de Baja California, México.

\begin{abstract}
This research determines the impact of some higher education and $R+D$ variables on different entrepreneurship outcomes in the states of Mexico during the period 2007-2017. By applying panel data analysis tracking the Mexican states over time and specifying an entrepreneurship model, the research shows that these variables affect the entrepreneurial outcomes heterogeneously depending on the type of venture; in particular, higher education and $R+D$ variables are not significant in explaining entrepreneurship in general but most of them are significant in explaining higher education and knowledge based entrepreneurship. These results harmonize with the perspectives suggesting the important role of the higher education and $R+D$ system in supporting entrepreneurship. Nevertheless, the results also underline the lack of relation of entrepreneurship with patents, posing questions on the degree of innovativeness of the ventures and the commercial use of inventions, the unequal distribution of higher education and $R+D$ activities across states and the limited scope of the public policy efforts as to impact overall entrepreneurship.
\end{abstract}

Keywords: Entrepreneurship; higher education; $R+D$; public policy. 


\section{Introduction}

Entrepreneurship is considered a crucial component of the mechanics operating for knowledge and $\mathrm{R}+\mathrm{D}$ activities to transform into innovations and their virtuous effects on societies (Audretsch, 2001; Aparicio et al., 2016). Consequently, countries have implemented policies to boost high impact entrepreneurship through institutional reforms, supporting agencies and programs and human capital investments to sustain research, development and innovation. Under this scenario, higher education institutions (HEI's) play an important role by forming human capital and providing a variety of entrepreneurial related services to students, faculty and society. Mexico, accordingly, has implemented a set of policies during the last decades to strengthen its human capital for professional specialization, research and innovation in order to catch up with other countries, including the financial support of the higher education system for capacity building, competitiveness and expansion; the encouragement of education attainment, upgrading and scientific skills in faculty; the organization of peer-reviewed quality accreditation and certification of the undergraduate and graduate programs; the creation of diverse programs to support research: grants for researchers, the strengthening of scientific infrastructures at universities and research centres; the funding of basic and applied research in accordance with the regional's needs; and the joint funding of innovation projects linking industry and academic institutions, among other actions. These policies have improved the higher education and $\mathrm{R}+\mathrm{D}$ performance indicators as suggested by the official sources the National Bureau of Statistics (INEGI) and the National Council for Science and Technology (CONACYT). This research determines the impact of these variables on different entrepreneurship outcomes in the states of Mexico during the period 2007-2017. The research shows that these variables affect the entrepreneurial outcomes heterogeneously; in particular, higher education and $\mathrm{R}+\mathrm{D}$ variables are not significant in explaining entrepreneurship in general but the higher education and knowledge based. The results provide an assessment of these policies from the standpoint of entrepreneurship which derive in policy implications.

\section{Entrepreneurship and the Role of Higher Education and R+D}

Entrepreneurship may be defined as opportunity recognition and enterprise formation (Parker, 2009) and it is affected by the environment shaping the economy, as it entails interdependencies between economic development and institutions, which in turn determine factors such as the quality of governance and policies, the access to capital, the knowledge context and other resources, and the perceptions of entrepreneurs. Some works contending the relation of different stages of the entrepreneurial process and venture types with economic development are Wennekers et al. (2005) and Acs et al. (2008); other support the relation between entrepreneurship and the institutional environment and the national cultures such as Bruton et al. (2010), Alvarez and Urbano (2011), Baumol and Strom (2007), Liñán and 
Fernandez-Serrano (2014), and Aparicio et al. (2016). Besides, the complex interactions between entrepreneurship and the macroeconomic, institutional and economic environment are Dvouletý (2018) and Brás \& Soukiazis (2018).

The system of HEI's has been considered as an important player in entrepreneurship by forming human capital, disseminating knowledge produced by scientific research and providing multiple services to society (Audretsch, 2014). HEI's are critical for the commercialization of ideas, contributing with a favorable environment leading to innovation and entrepreneurship (Rasmussen and Gulbrandsen, 2006). They also contribute by educating entrepreneurs through formal courses and extracurricular activities, by providing entrepreneurship related services (Walter et al., 2013; Bergmann et al, 2016) and through the entrepreneurial activity of faculty and students (Åstebro et al., 2012). Besides, some HEI's have assumed the entrepreneurial university concept commercializing research through patents, spin-offs, and the supporting of start-ups, the provision of venture capital, the construction of physical scientific infrastructures, the organization of university-industry programs, and the founding of research centers, incubators and technology transfer offices. Diverse studies have provided empirical evidence regarding the university's impact on students' entrepreneurial intentions and activity and, in general, on entrepreneurship at the different stages of the process: Chrisman et al. (1995) found new ventures created by faculty or with significant faculty inputs; Walter et al. (2013) and Bergmann et al. (2016) show the importance of entrepreneurship education and industry ties; Guerrero et al. (2017) emphasize the positive effects of incubators; and Geissler (2013) demonstrated the impact of the entrepreneurial climate at universities. Besides, Fini et al. (2017) show the positive effects of the university institutional framework changes toward entrepreneurship.

\section{Methodology}

The research is based on an unbalanced panel data tracking 30 of the 32 states of Mexico during the period 2007-2017 which is built from diverse data sets. The states of Campeche and Tabasco were dropped to avoid any bias derived from the preponderance of the oil industry. Entrepreneurship $\left(N_{i t}^{S}\right)$ statistics were obtained from two sources: the National Survey of Occupation and Employment (ENOE) elaborated by INEGI ${ }^{1}$ and the CONACYT ${ }^{2}$ National Registry of Scientific and Technological Institutions and Enterprises (RENIECYT). The former source surveys individuals aged 15 or more and tracks the number of those labeled as independent workers including the self-employees and the employers by state on a quarterly basis grouped according to education attainment. The CONACYT source

\footnotetext{
1 Instituto Nacional de Estadística y Geografía (INEGI) [National Institute of Statistics and Geography] https://www.inegi.org.mx/

2 Consejo Nacional de Ciencia y Tecnologia (Conacyt) [National Council for Science and Technology] https://www.siicyt.gob.mx/
} 
provides the number of organizations performing scientific and technological activities by state including mostly enterprises, but also private organizations and education institutions. The different types of entrepreneurs $\left(N_{i t}^{S}\right)$ included in the study are total (ntotalp $p_{i t}$ ), basic educated (nebasp $p_{i t}$ ), medium-high higher educated (nemsp $p_{i t}$ ) and knowledge based (etecp $\left.p_{i t}\right)$ relative to population. The context variable representing the level of development is the real per capita GDP (GDPp) provided by INEGI. The higher education and $\mathrm{R}+\mathrm{D}$ variables $(X)$ are the System of National Researchers (SNI) members-certified researchers (snip), the Faculty Development Program (PRODEP) certified faculty (prodepp), Patents (patp) and Talent ( $t a l)$. The first three $X$-variables are transformed in per 100 thousand people terms and were obtained from the website Comparative Study of Mexican Universities (ECUM) ${ }^{3}$ hosted by the National Autonomous University of Mexico (UNAM). Talent ( $t a l$ ) is expressed as the percentage of the population aged 25 or older who has either higher or technical education and was provided by The Institute for Competitiveness (IMCO) ${ }^{4}$ using INEGI data. The $X$ variables were selected after a correlation analysis including in addition higher education students and undergraduate and graduate programs.

A log transformed Cobb-Douglas function of equation 1 is proposed for the empirical work.

$$
l N_{i t}^{s}=\hat{\beta}+\hat{\beta}_{c}+\hat{\beta}_{y} l y_{i t}+\sum_{j}^{K} \hat{\beta}_{X}^{j} l X_{i t}^{j}+\epsilon_{i t}
$$

Where $l N_{i t}^{S}$ represents the natural $\log$ of the number of entrepreneurs of type $S ; \hat{\beta}$ is the intercept and the parameters $\hat{\beta}_{y}$ and $\hat{\beta}_{X}^{j}$ are associated to the natural log of the level of economic development $\left(y_{i t}\right)$ capturing also the general context and the set of $K$ variables $X_{i t}^{j}$ depicting higher education and $\mathrm{R}+\mathrm{D}$ correspondingly. The sub-indexes $i$ and $t$ refer to the individual states and time included in the regression. The parameters associated with the lefthand variables $\left(\hat{\beta}_{y}, \hat{\beta}_{y 2}\right.$ and $\left.\hat{\beta}_{X}^{j}\right)$ are interpreted as the elasticities of the number of entrepreneurs to $1 \%$ change in their corresponding variables. A dummy variable to capture the effect of the 2008-2010 global crisis is included with the parameter $\hat{\beta}_{c}$. The error term is given by $\epsilon_{i t}=\alpha_{i}+n_{i t}$ integrated by an individual time invariant component $\alpha_{i}$ and an error term $n_{i t}$ which vary randomly across individuals and time periods. The assumption regarding $\alpha_{i}$ requires selecting Random Effects (RE) or Fixed Effects (FE).

\footnotetext{
${ }^{3}$ Estudio Comparativo de Universidades Mexicanas (ECUM) [Comparative Study of Mexican Universities], Universidad Nacional Autónoma de México (UNAM) http://www.execum.unam.mx/

${ }^{4}$ Instituto Nacional para la Competitividad (IMCO) [Mexican Institute for Competitiveness] https://imco.org.mx/
} 


\section{Econometric results and discussions}

The econometric results are reported in Table 1. The models are estimated using 241 observations, given the lack of data of some states; they are global significant and exhibit an acceptable fit. The FE was accepted only in one regression. The lGDPp (y) variations are significant in explaining all types of entrepreneurs - except for the total- although with some divergences between ventures. On the one hand, for the basic educated entreprenerus (lnebas) of regression 2, the relation with respect the changes in economic development is linear and negative suggesting that as the states' per capita GDP reduces these types of ventures increases. The medium high-higher educated entrepreneurs (lnems) and the technological based (letec) represented in the regressions 3 and 4 correspondingly have a positive linear relation with respect GDPp. Hence, the level of development is associated differentialy to the entreprenerual outcomes reflecting their necessity-opportunity nature of the ventures and their differential responses to the economic activity.

Table 1. Econometric results.

\begin{tabular}{|c|c|c|c|c|c|c|c|c|}
\hline \multirow[b]{2}{*}{$\beta$} & \multicolumn{2}{|c|}{$\begin{array}{c}(1) \\
\text { lntotal }_{\text {it }}\end{array}$} & \multicolumn{2}{|c|}{$\begin{array}{c}(2) \\
\text { Inebas it }\end{array}$} & \multicolumn{2}{|c|}{$\begin{array}{c}(3) \\
\text { Inems it }\end{array}$} & \multicolumn{2}{|c|}{$\begin{array}{c}\text { (4) } \\
\text { letec }\end{array}$} \\
\hline & Coef. & $\mathrm{p}$ & Coef. & $\mathrm{p}$ & Coef. & $p$ & Coef. & $p$ \\
\hline$l_{G F P p_{i t}}$ & -0.160 & & -0.392 & $*$ & 0.446 & * & 1.153 & $*$ \\
\hline lprodepp $_{\text {it }}$ & 0.014 & & 0.009 & & 0.045 & $*$ & 0.152 & $*$ \\
\hline$l_{\text {snip }}$ it & 0.014 & & 0.006 & & 0.059 & $*$ & 0.096 & $*$ \\
\hline ltal $_{i t}$ & 0.152 & & 0.113 & & 0.169 & & -0.584 & $* *$ \\
\hline lpatp $_{i t}$ & 0.012 & & 0.008 & & 0.021 & & 0.043 & \\
\hline dcrisis08 & -0.105 & $*$ & -0.086 & $*$ & -0.188 & * & -0.054 & \\
\hline$c$ & 13.67 & * & 15.71 & $*$ & 6.31 & * & -4.63 & \\
\hline Obs & 241 & & 241 & & 241 & & 241 & \\
\hline $\mathrm{i}$ & 30 & & 30 & & 30 & & 30 & \\
\hline Within R2 & 0.39 & & 0.21 & & 0.60 & & 0.35 & \\
\hline F-Test/Wald Chi2 & 125.48 & & 55.72 & & 300.59 & & 18.69 & \\
\hline Prob & 0.00 & & 0.00 & & 0.00 & & 0.00 & \\
\hline rho & 0.98 & & 0.98 & & 0.96 & & 0.35 & \\
\hline F-Test (u i=0) & & & & & & & 32.84 & \\
\hline Prob $>$ chi 2 & & & & & & & 0.00 & \\
\hline Hausman Chi2 & 9.45 & & 4.56 & & 4.30 & & 76.96 & \\
\hline Hausman prob & 0.15 & & 0.60 & & 0.63 & & 0.00 & \\
\hline Model & $\mathrm{RE}$ & & $\mathrm{RE}$ & & RE & & FE & \\
\hline
\end{tabular}

The $X$-variables are not significant for the total number of entreprenerus (lntotal) nor for the basic educated (lnebas) (1 and 2): the later result does not surprise given the nature of the ventures started by the low educated individuals; the former reveals the predominant traditional and necessity-driven nature of entrepreneurship in Mexico and the limited size of the knowledge and the $\mathrm{R}+\mathrm{D}$ sector as to impact the general level of entrepreneurship. As for the medium high-higher educated entrepreneurs (lnems) (regression 3), lsnip and also the lproepp, which represent indicators of higher education and $\mathrm{R}+\mathrm{D}$ and human capital 
specialization, are significant though small in impact as compared to the technological based (letec). This result may be due to the size of the sector of lnems which is much larger than the letec, making much more difficult that the limited higher education and $\mathrm{R}+\mathrm{D}$ sector impulses perceptibly that group of firms. Talent (ltal) and patents (lpatp) are not significant in these cases. As for the technological based (letec), the significant $X$ variables are lsnip, lprodepp and ltal, providing additional evidence on their relevance in contrast to entrepreneurship in general and the basic educated entrepreneris (lnbas). The $X$-variables lsnip and lprodepp have a significant positive effect on letec. The effect of talent ltal on entrepreneurship turned out to be negative, reflecting the hindering effect of education on entrepreneurship as proposed in Kangasharju and Pekkala (2002) and Sluis et al. (2008).

The $X$-variables in general, represented by those variables which were incorporated in the econometric model (lsnip, lprodepp, ltal and lpat) but correlated with the excluded $X$ variables, illustrate the effect of the higher education and $\mathrm{R}+\mathrm{D}$ system in supporting higher educated and technological based entrepreneurs in Mexico, harmonizing with some perspectives supporting the important role of universities: Rasmussen and Gulbrandsen (2006); Åstebro et al. (2012); Walter et al. (2013); Audretsch, (2014); Bergmann et al. (2016). The results also reflect the important role that faculty professional and scientific specialization in individuals may be playing in supporting higher educated and technological based ventures either through faculty entrepreneurship, associates or university-enterprise linkages, which is consistent with Masakure (2015) and Jimenez et al. (2015). The significance of lsnip and lproepp in explaining the entrepreneurs of higher quality type may suggest the prevalence of faculty entrepreneurship as earlier proposed by Chrisman et al. (1995) and Åstebro et al. (2012). Despite the statistical significance of lprodepp and lsnip, the per capita number of patents (lpatp) turned out to be not significant, opposing the idea that entrepreneurship works as conduit for $\mathrm{R}+\mathrm{D}$ to transform into innovation either through start-ups or spin-offs. Diverse studies report effects of patents on entrepreneurship, although they converge in that these effects are rather small: Goel \& Saunoris (2017) reports evidence supporting that patents affect more startup entrepreneurship as compared to the modest effect on overall entrepreneurship; Meyer (2006) reports that despite start-ups and spin-offs play a role in transferring technologies invented by scholars, large firms and established small and medium-sized enterprises account for a much greater share of utilized academic patents. Thus, the null impact of patents in entrepreneurship reported previously may be due either to the rather small number of patents per capita, their lack of commercial use given their pure academic nature, and their commercialization via an existing firm through licensing or transferring. 


\section{Final remarks}

The research results harmonize with the perspectives suggesting the important role of the higher education and $\mathrm{R}+\mathrm{D}$ system in supporting entrepreneurship, maintained by various mechanisms such as professional and scientific specialization of individuals, faculty entrepreneurship and university-industry linkages. The results indirectly suggest that public policies improving the higher education and $\mathrm{R}+\mathrm{D}$ system have also impacted entrepreneurship. However, the results also uncover the limited scope of such policy efforts as to impact overall entrepreneurship, the inequalities of higher education and $\mathrm{R}+\mathrm{D}$ indictors across states, affecting also the nature of their entrepreneurial outcomes; and the limited patenting activity, which questions the commercial potential of inventions and the innovativeness of the ventures and limits the impact from higher education and $\mathrm{R}+\mathrm{D}$. The research provides some insights for public policy.

The public resources and programs should be augmented to intensify human capital formation for specialization and scientific development and entrepreneurship. This requires a shift in the higher education policy as to include more decisively entrepreneurship content to encourage the higher education institutions pursue programs and specific actions to support entrepreneurial education and startups for students, faculty and society. Private universities have taken steps forward toward an entrepreneurial education but the public system of HEI's must catch up in order to provide a higher degree of employability and innovation potential to their graduates and faculty taking advantage of their relatively stronger $\mathrm{R}+\mathrm{D}$ structures. Moreover, the universities should improve their legal frameworks as to encourage the creation of intellectual property rights and facilitate transfers and commercialization of inventions either through university entrepreneurship or licensing to enhance high impact ventures. It is not that the public HEI's do not have initiatives associated to entrepreneurship but their scope is limited to some general actions and opportunities, which are disperse and uneven across departments, and usually not centralized and embedded in an institutional framework ex profeso to encourage entrepreneurship at the different stages of the entrepreneurial process. In general, these initiatives should be embedded in a proper system of linkages of universities with the industry and society and programs supporting the interactions of faculty and students with those sectors and other relevant actors to encourage collaboration.

\section{References}

Acs Z.J., Sameeksha Desai \& Jolanda Hessels. (2008). Entrepreneurship, economic development and institutions", Small Business Economics, (31):219-234

Aparicio, S., Urbano, D., \& Audretsch, D. (2016). Institutional factors, opportunity entrepreneurship and economic growth: Panel data evidence. Technological Forecasting and Social Change, 102, 45-61 
Åstebro, T., Bazzazian, N., \&Braguinsky, S. (2012). Startups by recent university graduates and their faculty: Implications for university entrepreneurship policy. Research policy, 41(4), 663-677

Audretsch, D. B. (2001). Research issues relating to structure, competition, and performance of small technology-based firms. Small business economics, 16(1): 37-51.

Audretsch, D. B. (2014). From the entrepreneurial university to the university for the entrepreneurial society. The Journal of Technology Transfer, 39(3), 313-321.

Bergmann, H., Hundt, C., y Sternberg, R. (2016). What makes student entrepreneurs? On the relevance (and irrelevance) of the university and the regional context for student startups. Small Business Economics, 47(1), 53-76.

Brás, G. R., \& Soukiazis, E. (2018). The Determinants of Entrepreneurship at the Country Level: A Panel Data Approach. Entrepreneurship Research Journal, 9(4).

Dvouletý, O. (2018). How to analyse determinants of entrepreneurship and self-employment at the country level? A methodological contribution. Journal of Business Venturing Insights, 9, 92-99.

Fini, R., Fu, K., Mathisen, M. T., Rasmussen, E., \& Wright, M. (2017). Institutional determinants of university spin-off quantity and quality: a longitudinal, multilevel, crosscountry study. Small Business Economics, 48(2), 361-391.

Geissler, M. (2013). Determinanten des Vorgrundungsprozesses. Wiesbaden: Springer Fachmedien Wiesbaden

Goel, R. K., \& Saunoris, J. W. (2017). Dynamics of knowledge spillovers from patents to entrepreneurship: Evidence across entrepreneurship types. Contemporary Economic Policy, 35(4), 700-715.

Guerrero, M., Urbano, D., \& Gajón, E. (2017). Higher Education Entrepreneurial Ecosystems: Exploring the Role of Business Incubators in an Emerging Economy. International Review of Entrepreneurship, 15(2).

Jiménez, A., Palmero-Cámara, C., González-Santos, M. J., González-Bernal, J., \& JiménezEguizábal, J. A. (2015). The impact of educational levels on formal and informal entrepreneurship. BRQ Business Research Quarterly, 18(3), 204-212

Kangasharju, A., y Pekkala, S. (2002). The role of education in self-employment success in Finland. Growth and change, 33(2), 216-237.

Liñán, F., \& Fernandez-Serrano, J. (2014). National culture, entrepreneurship and economic development: different patterns across the European Union. Small Business Economics, 42(4), 685-701.

Masakure, O. (2015). Education and entrepreneurship in Canada: evidence from (repeated) cross-sectional data. Education Economics, 23(6), 693-712.

Parker, S. (2009). The Economics of Entrepreneurship. Cambridge: Cambridge University Press.

Sluis Van der, J., Praag Van, M., y Vijverberg, W. (2008). Education and entrepreneurship selection and performance: A review of the empirical literature. Journal of economic surveys, 22(5), 795-841. 
Walter, S. G., Parboteeah, K. P., \& Walter, A. (2013). University departments and selfemployment intentions of business students: a cross-level analysis. Entrepreneurship Theory and Practice, 37(2), 175-200.

Wennekers, S., Van Wennekers, A., Thurik, R., \& Reynolds, P. (2005). Nascent entrepreneurship and the level of economic development. Small business economics, 24(3), 293- 